\title{
Research Paper \\ Investigating the Relationship Between Terms of Trade Shocks and Private Savings in Iran
}

\author{
*Azam Mohammadzadeh ${ }^{1}$
}

1. PhD. in Financial Economics, Department of Economics, Faculty of Management and Economics, University of Sistan and Baluchestan, Zahedan, Iran.

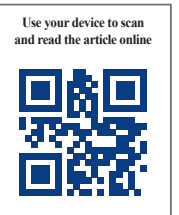

Citation Mohammadzadeh, A. (2018). Investigating the Relationship Between Terms of Trade Shocks and Private Savings in Iran. Quarterly Journal of the Macro and Strategic Policies, 6(3), 414-433. http:// dx.doi.org/10.32598/JMSP.6.3.414

dol': http://dx.doi.org/10.32598/JMSP.6.3.414

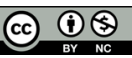

Funding: See Page 430

Received: 31 Jul 2016

Accepted: 11 Mar 2018

Available Online: 23 Sep 2018

Key words:

Private savings per capita, Trade shocks, Terms of trade, GMM method

\section{ABSTRACT}

Investigation of factors affecting the savings is one of the important issues in developed and the developing countries in recent studies. The main purpose of this paper is to examine the relationship between trade shocks and private savings per capita in Iran between 1963 and 2015. In this regard, the models were estimated using the GMM and OLS methods. In order to enter trade shocks in the model, standard Hodrick-Prescott (HP) filter was used. This filter separates trade shocks (in terms of permanent and temporary shocks) and analyze their effects on per capita private savings. The results of the model estimation show that savings in previous period and trade shocks had a significant effect on savings so that they explained $78 \%$ of variance in savings. The estimation results suggest that the trade shocks have positive effect on savings, but trade fluctuations has a negative effect on savings. Temporary shocks have a greater effect on the savings compared to permanent shocks.

JEL Classification: D10, E01, E20

\section{Corresponding Author:}

Azam Mohammadzadeh, PhD.

Address: Department of Economics, Faculty of Management and Economics, University of Sistan and Baluchestan, Zahedan, Iran.

Tel: +98 (930) 9245687

E-mail: az.mohammadzadeh@gmail.com 


\section{رابطه بين تكانههاي تجارى و يسانداز خصوصى در ايران}

* |عظم محمدزاده *

ا - دكترى اقتصاد مالى، كروه علوم اقتصادى، دانشكده مديريت و اقتصاد، دانشعاه سيستان و بلوجهستان، زاهدان، ايران.

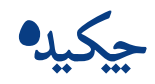

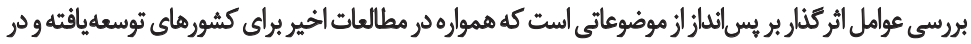

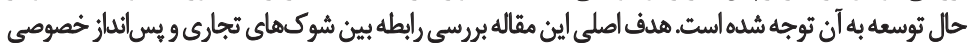

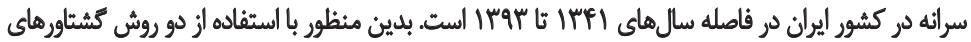

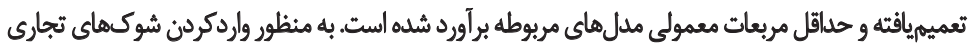

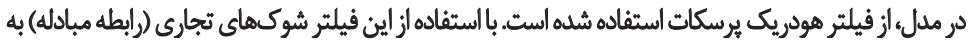

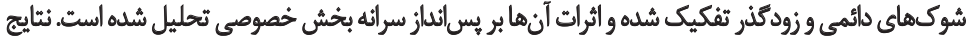

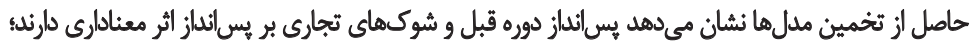

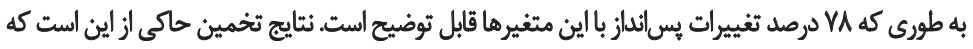

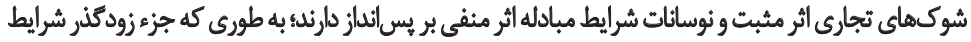

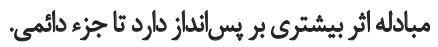
طبقهبندى D10, E01, E20 :JEL
تاريخ دريافت: • • مرداد هوس| تاريخيذيرش:·r|سفندوهوبا

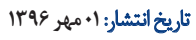

:Lofilguls

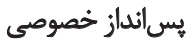
سرائه، شوكهاني تجارى، رابطه مبادله،

روش تجاري، رابطه 


\section{dalo}

هر كشورى براى رسيدن به رشد و توسعه اقتصادى نيازمند سرمايهَذارى بوده و يسانداز شرط لازم براى

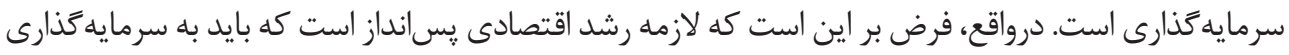

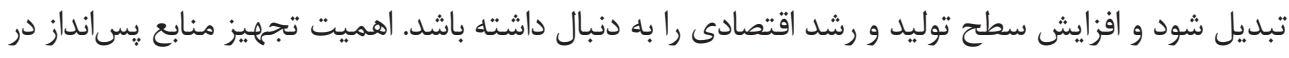

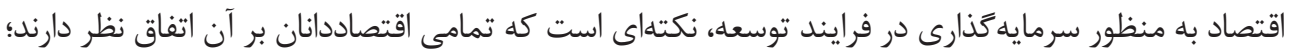

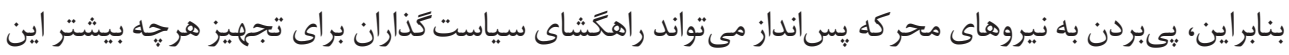

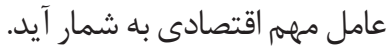

\section{1- ادبيات موضوع}

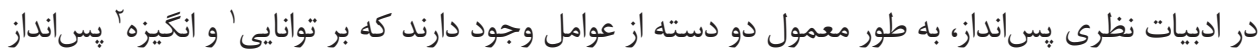

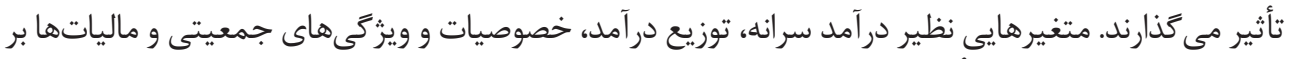

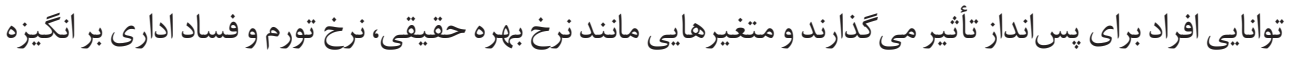

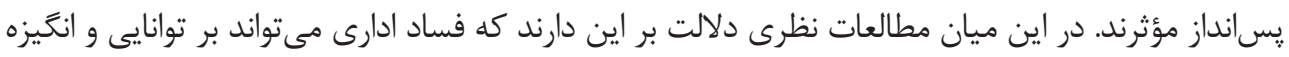

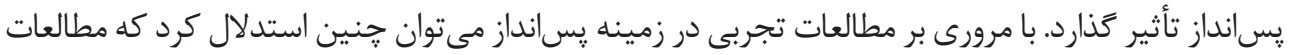

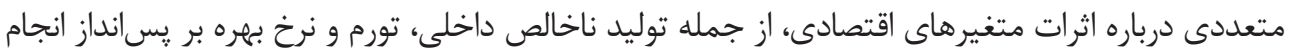

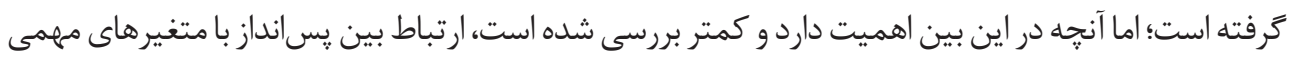
همجون شوكهاى تجارى است كه موضوع اين مقاله است است دميت

موضوع مطالعات تجربى عوامل اثرگذار بر يسانداز از موضوعاتى است كه همواره در مطالعات اخير براى تو

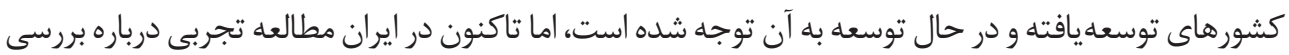

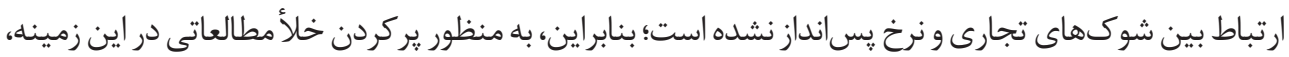

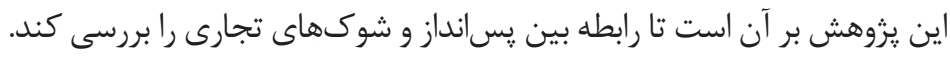

ادبيات كستردهاى درباره شوكهاى تجارى و توضيح آن در عملكرد اقتصادى كلان وجود دارد. سؤال مهلم

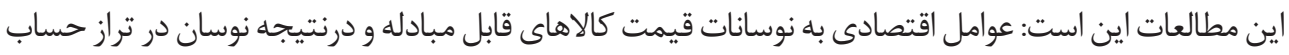

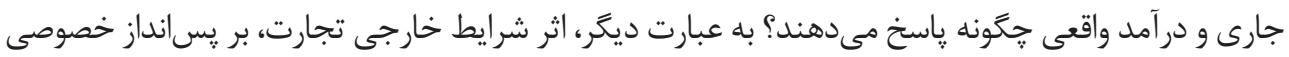

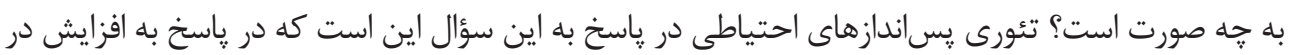

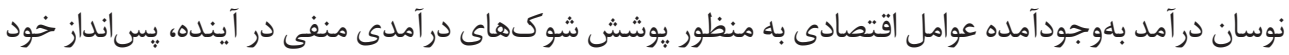
را افزايش مى دهند.

شرايط تجارت يا همان رابطه مبادله يكى از معيارهاى ارزيابى ميزان بهرهمندى كشورها از منافع تجارى 
به شمار مىرود؛ از اين رو جايگاه ويزهاى در اقتصاد بين الملل دارد. شوكهاى ناشى از اين تغيير مىتوانند

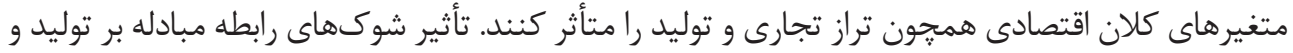

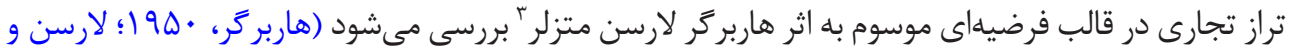
متزلر، • (190).

وجود ارتباط مثبت ميان شوكهاى رابطه مبادله و تراز تجارى مؤيد اثر هاربر رَ لارسن متزلر است. اين فرضيه

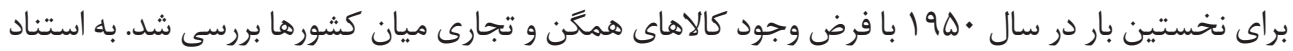

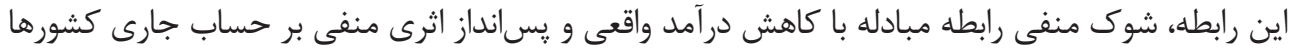

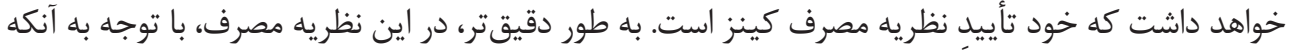

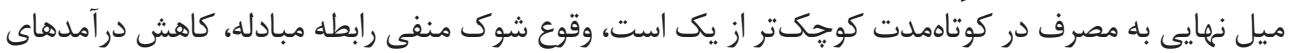

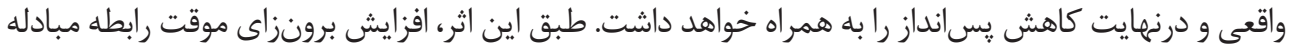

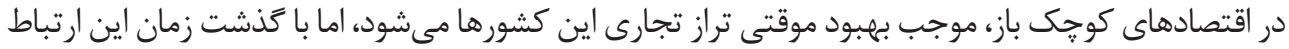

$$
\text { از بين مىرود و ميرا ميىشود. }
$$

با توجه به مطالب مطرحشده درباره اهميت موضوع بررسى رابطه بين يسانداز و شرايط مبادله، در اين مقاله

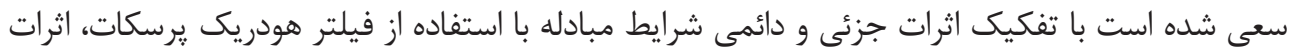

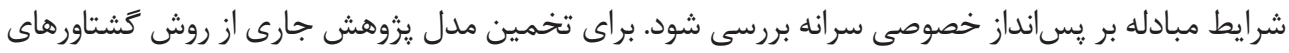

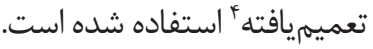

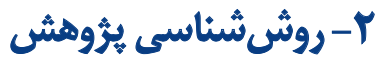

در اين بخش ابتدا مطالعات داخلى و خارجى انجامشده در زمينه عوامل مؤثر بر پسانداز، بررسى شده است.

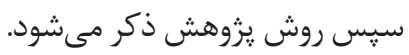

\section{|-}

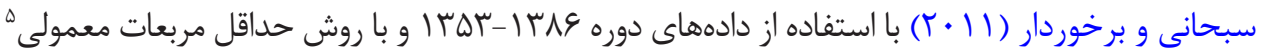

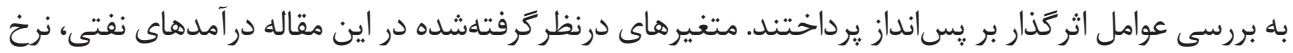

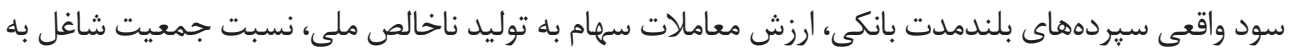

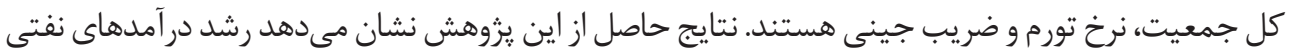

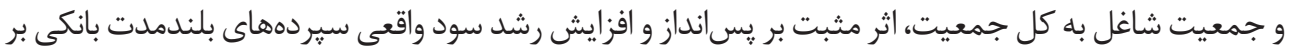
يسانداز بخش خصوصى، اثر منفى دارد.

3. Harberger-Laursen-Metzler (HLM) effect

4. Generalized Method of Moments (GMM)

5. Ordinary Least Squares (OLS) 


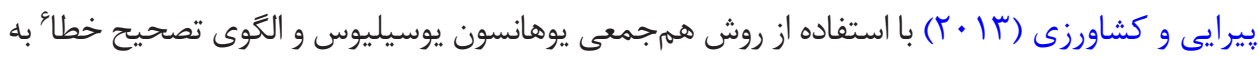

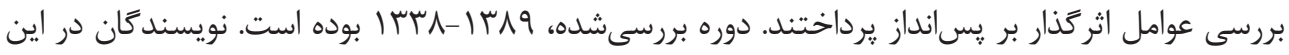

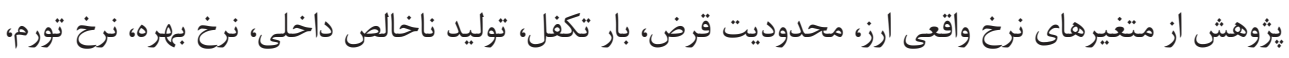

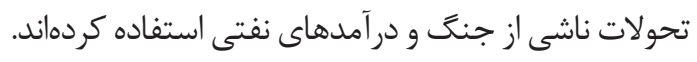

نتايج تخمين مدل ها نشان مى دهد كه اثر توليد ناخالص داخلى، نرخ بهره و شوكهاى حاصل از درآمدهاى

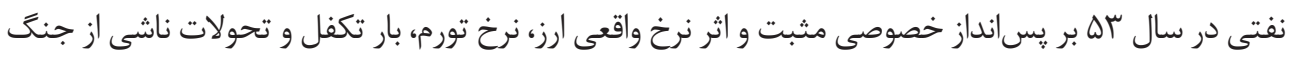

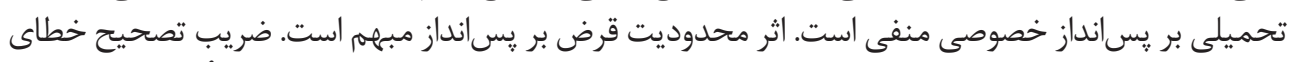

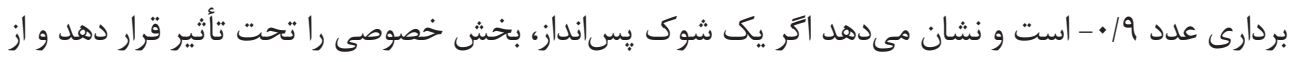

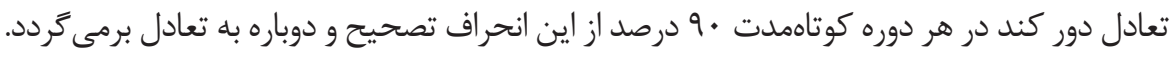

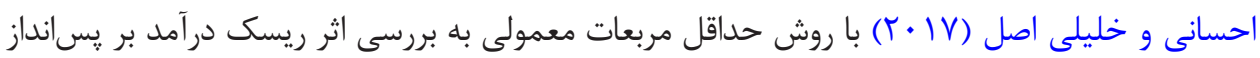

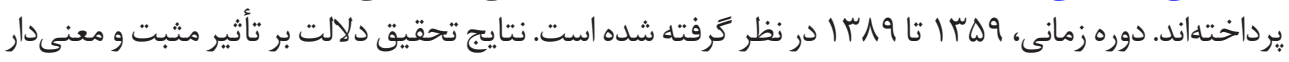

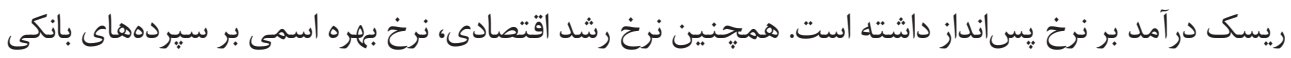
اثر مثبت دارد.

7. Economic Confidence Model (ECM)

جدول ا. خلاصهاي از مطالعات داخلى انجامشده درباره عوامل اثر كذار بر خيسانداز

ثتايج

متغير هاي ميرل

نويسندكان ورود و منطقيه

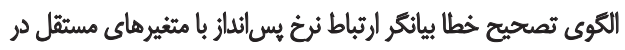

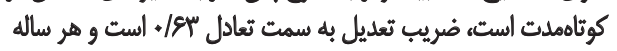

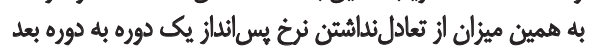

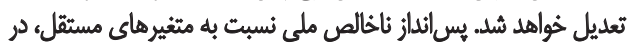

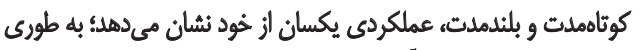

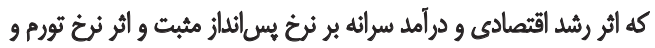

رشيد اقتصادى، درآمد سرانه،

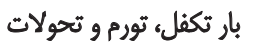
ناشي ازئ انقلاب

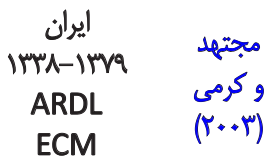

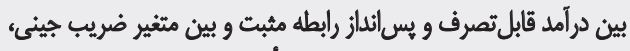

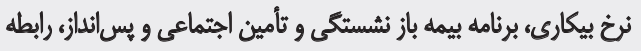

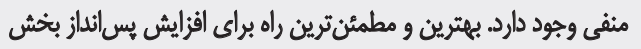
خصوصى بهبود وضعيت بازارهاي مالى است.

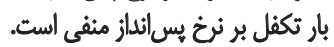

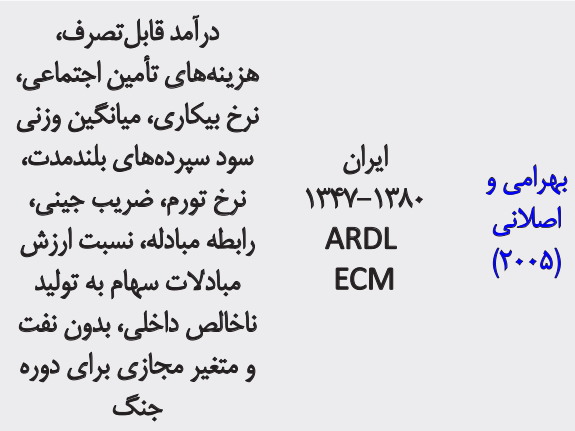




\section{تتايج}

\section{متغيرهاى مدل}

نسبت اعتبارات بخش نواله

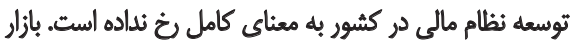

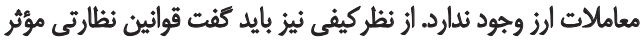

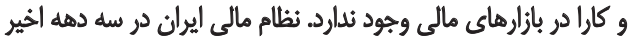

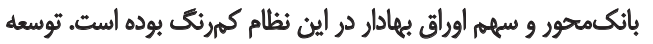

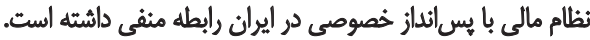

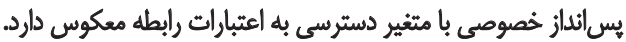

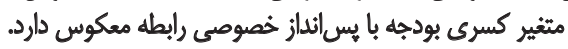
رشد اقتصادى در كوتاممدت و نوسانات درأمدهاى نفتى به ترثيب تأثير

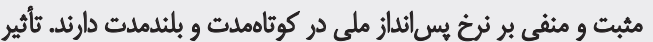

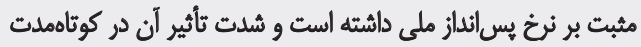
بيش أز بلندمدت الست.

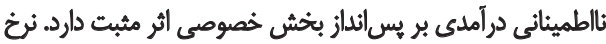

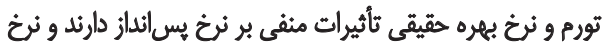

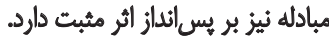

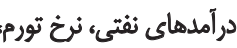
ئخ بهره و رابطه مبادله نيل

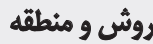

مورديخونش

\section{ن مويسندكان}

خصوصي باه توليد ثاخخالص

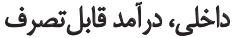

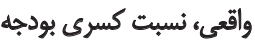

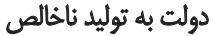

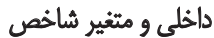
توسعه مالى
ايران

|Tre-|rA|

همجمعى

يوهائسون

ابريشمى

نامور (Y+r)

يوسيليوس يومانسون

رئد اقتصادي، نوسائات

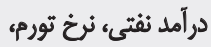

ARDL

هوشمندي

ECM

$(r+. q)$
GMM

GARCH
عباسى و هـان $(r+14)$

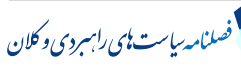

علاوه بر موارد يِيشَفته، جدول شماره ا نيز خلاصهاى از مطالعات داخلى درباره عوامل اثرَذار بر يسانداز را نشان مى دهد.

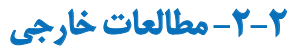

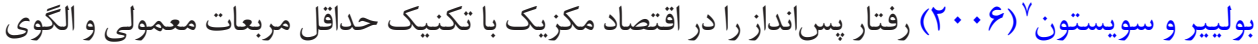

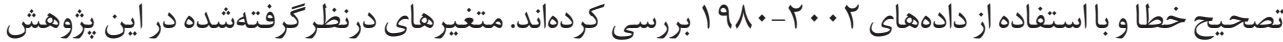

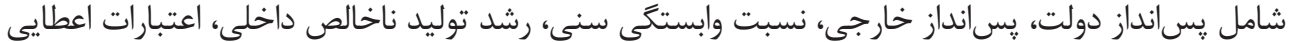

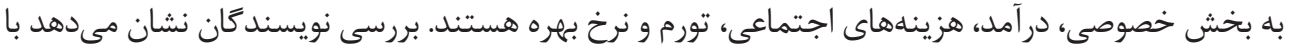

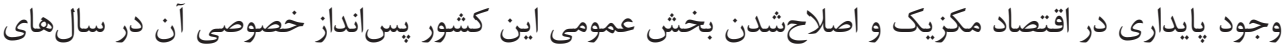

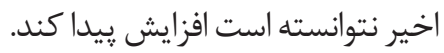

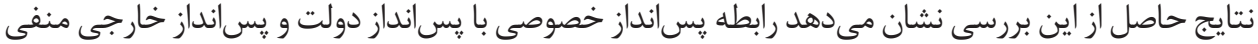

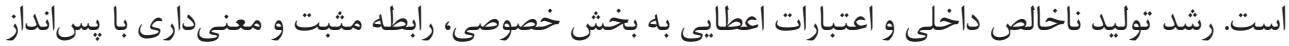

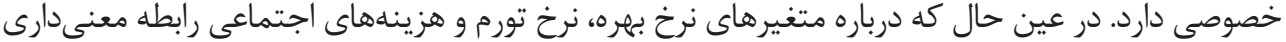
در اين تحقيق ييدا نشده است. 


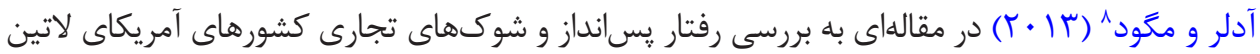

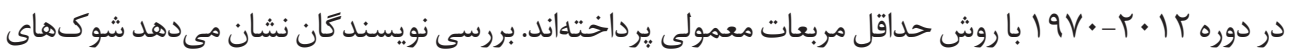

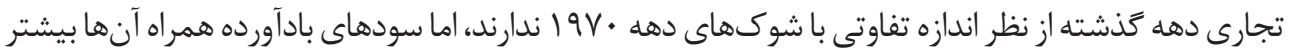

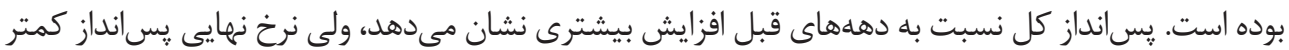

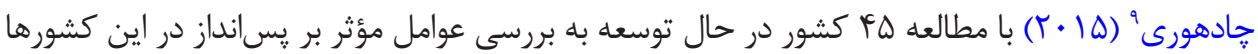

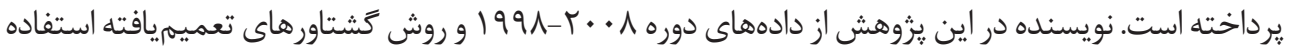

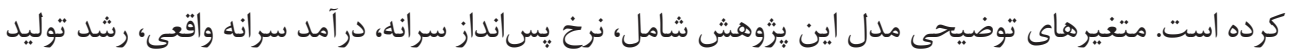
ناخالص داخلى سرانه، سطح يولىشدن M2 M (حجم يول) بر

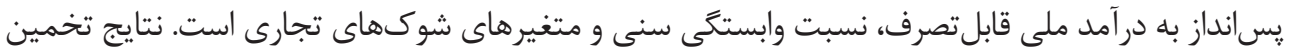

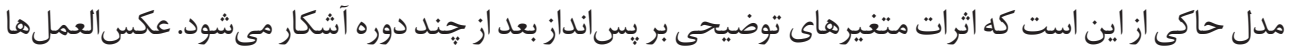

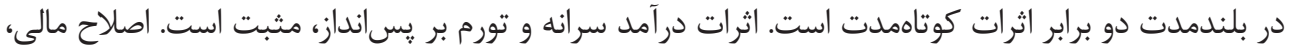

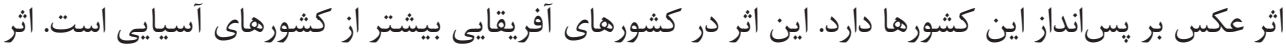
شوك هاى تجارى بر يسانداز مثبت است. شوكهاى موقت اثر بيشترى دار دارند.

علاوه بر موارد يبش گَفته، جدول شماره ؟ نيز خلاصهاى از مطالعات خارجى درباره عوامل اثر گذار بر يسانداز رانشان مىدهد.

8. Adler \& Magud

9. Chowdhury

جدول r. خلاصهاي از مطالعات خارجى انجامشده درباره عوامل اثركنار بر هي انداز

\begin{tabular}{|c|c|c|c|}
\hline نتايج & متغير هاى مدل & مورد و يثوهش مثطقد & نويسيندكان \\
\hline 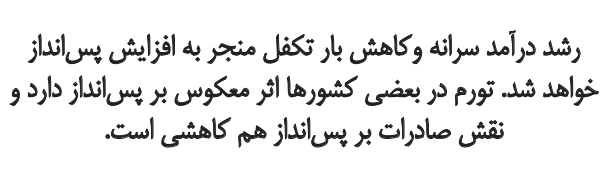 & 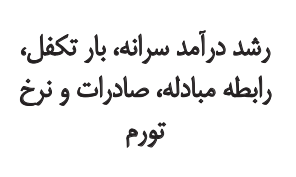 & حداثل مربعات & $\begin{array}{l}\text { لاهيرى } \\
\text { (1941) }\end{array}$ \\
\hline 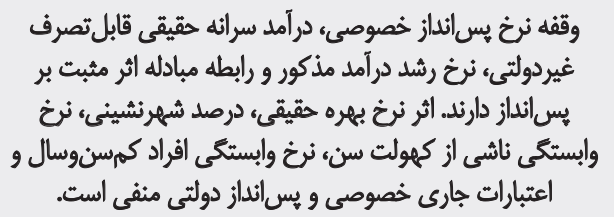 & 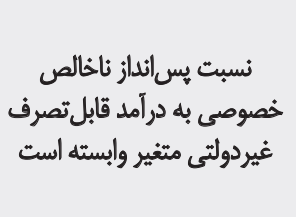 & 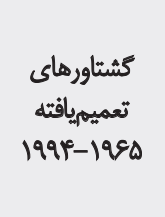 & 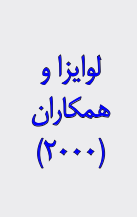 \\
\hline
\end{tabular}




\section{نتايع}

\section{مثغيرهاى مدل}

روش و منطقه

هورد بيؤوهش مونش

نويسندكان

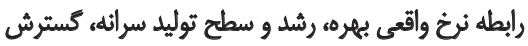

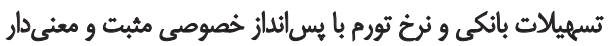

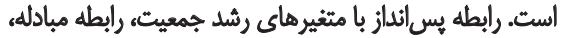

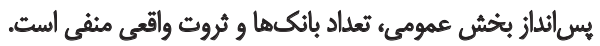

ظرفيت قرضدهى در هر ب كثشور رابطه منفى با نرخ يسانداز

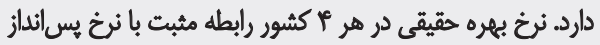

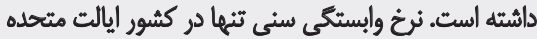

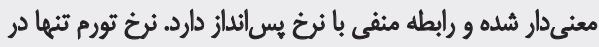

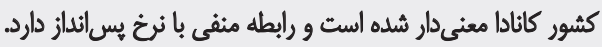

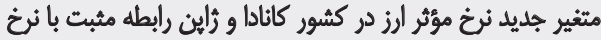

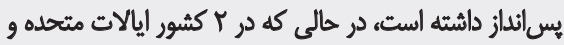
بريثائيا رابطه هنفي دارد.

اللوكي نخ يس أنداز كل براي كشور كره جنوبي با نظريه سيكل

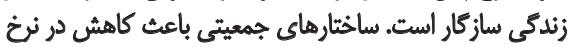

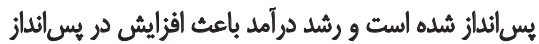

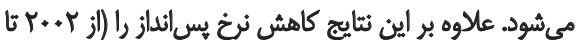

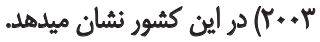

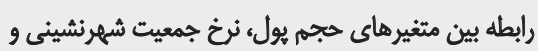

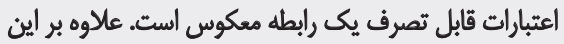

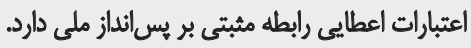

نغخ رشد سرائه واقثعى درآهد

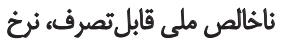

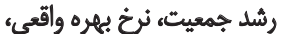
ثروت واقعى، نسرانه واقعى درآثد ثاخالص هلي قابايل تصرفه بلهني

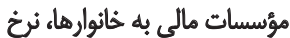
تورجه، رابطه مبادله، يس اندانداز

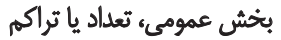

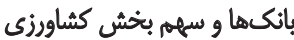

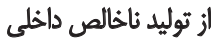

توليد ناخالص داخلى حقيقى،

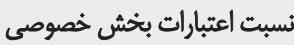
به توليد ناخالص داخلي حقيقي خصي و نسبت حجم نقدينكى به توليد ناليد

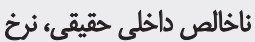

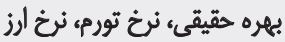

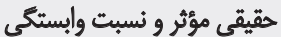

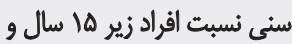
بالاي هاء سال به كل جمعيت

ويسانداز كل، هيسانداز خارجي،

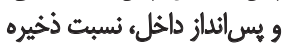

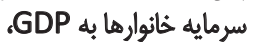

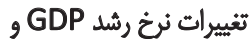
كواى ولى 19V. r... (r..Q ) سالهاى عمر مورد ائتظار متعير هائ يسانداز ملي، درآهد

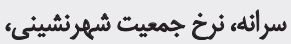
حجم يول و اعتبارات قابل جنيل تصرف
كائاداء رُايني،

ايالت متحده و رواين

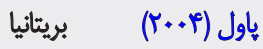

19DF-12M

ECM

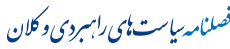

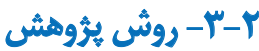

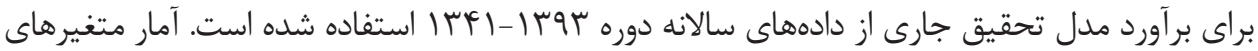
استفادهشه در مدل، از بانك اطلاعات سرى زمانى بانك مركزى استخر اج اج شده است. متغيرهاى مدره مورداستفاده 


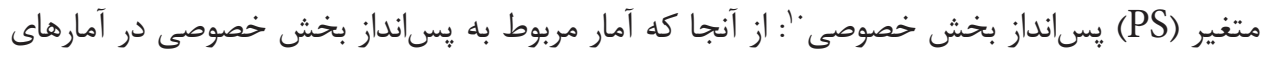

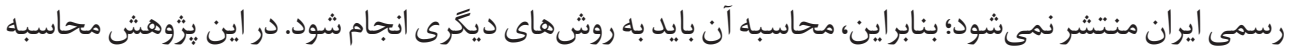

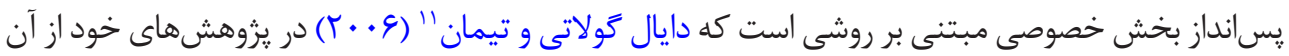

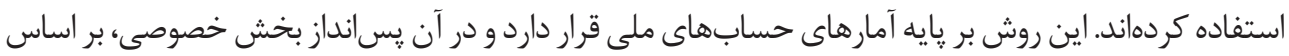

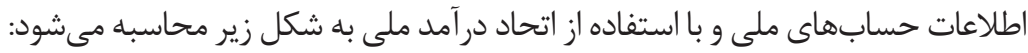

\section{$G F I+P F I+P C O N+G C O N+(X n o-M)=Y n o=P C O N+P S+T$}

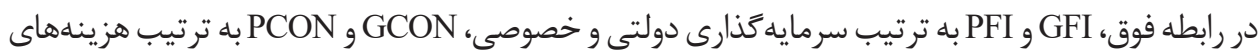

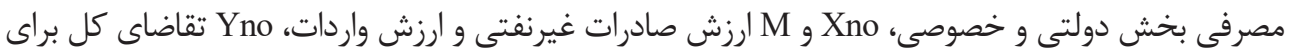

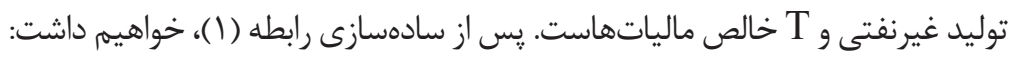

\section{$(G F I+P F I)-(T-G C O N)+(X n o-M)=P S$}

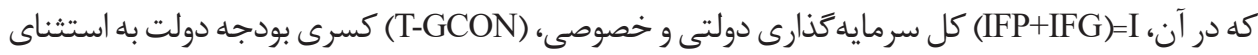
مخارج سرمايهَذارى دولت، (Xno-M) خالص صادرات غيرنفتى و

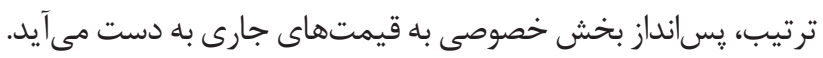

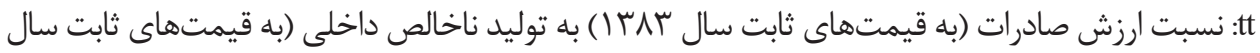

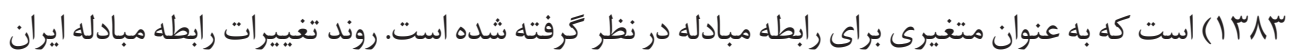

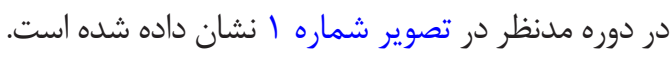
متغير VT كه نشاندهنده نرخ رشد شرايط مبادله است و به صورت زير قابلمحاسبه است (جادهورى،

$$
V T=\left[\left(\frac{1}{K}\right) \sum\left(\log Q_{t-i-1}-\log Q_{t-i-2}\right)^{2}\right]^{\frac{1}{2}}
$$

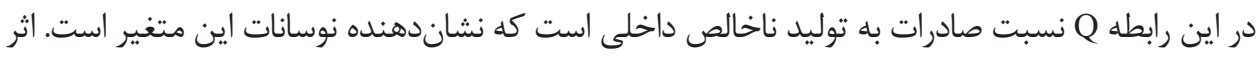

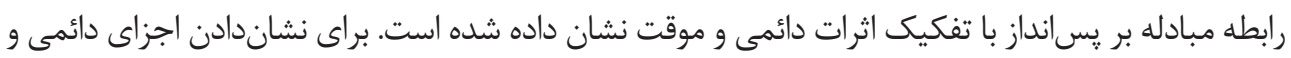

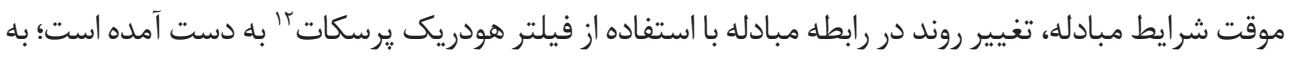




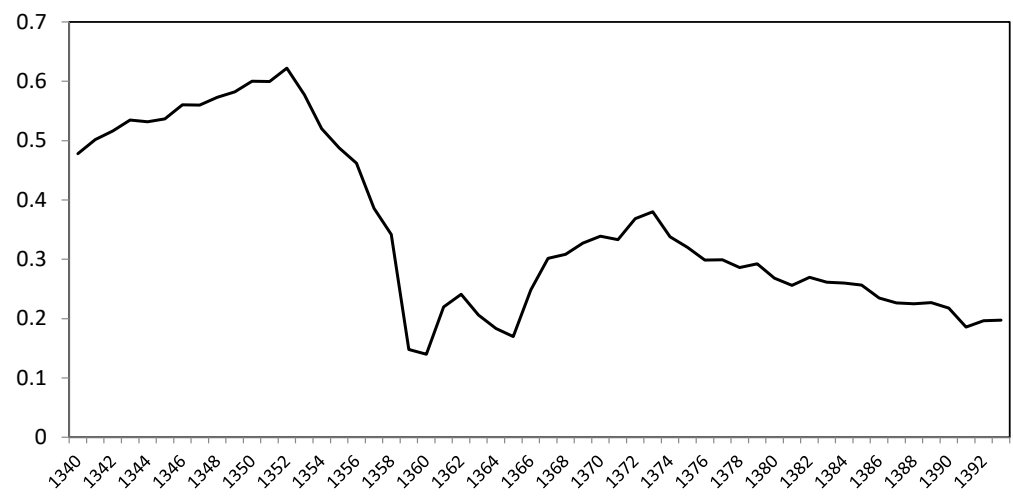

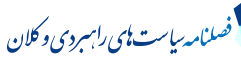

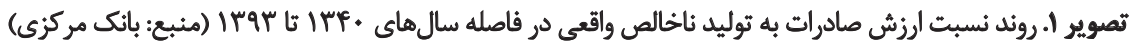

طورى كه متغير TOTT نشاندهنده اجزاى موقت در تغيير روند شرايط مبادله و PTOT، اجزاى دائمى در تغيير

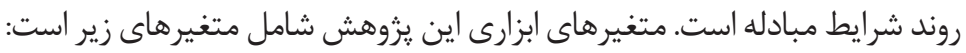

دائم : هرج جند اثر درآمد بر : يسانداز در مدلهاى تئوريكى قاطع نيست، اما اين متغير در فرضيه درآمد

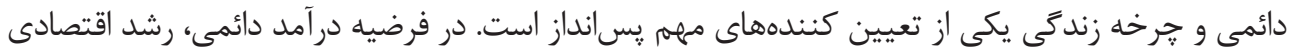

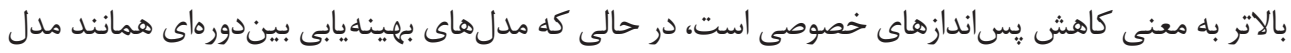

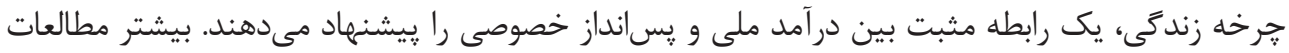

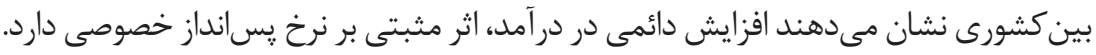

بنه

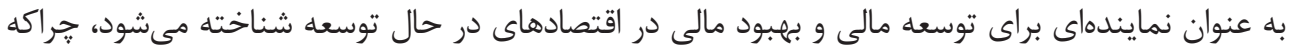

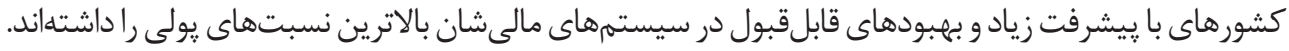

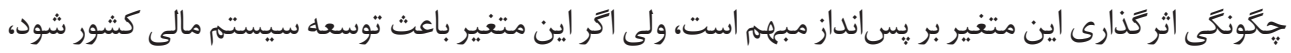

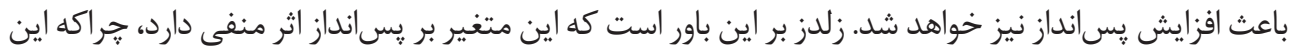

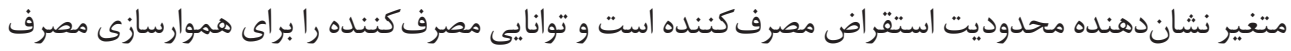
در فرايند وامخيرى كاهش مى ندهد.

مثيتج :GRPCY رشد توليد ناخالص داخلى حقيقى سرانه كه اثرات جرخه تجارى را در نظر مى گيرد و بايد اثر مثبتى بر يسانداز داشته باشد.

شاغلين DEP نسبت وابستخى اثر جرخه زند

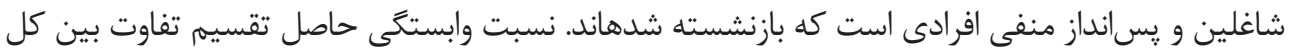




\section{جمعيت و نيروى كار به كل جمعيت است.}

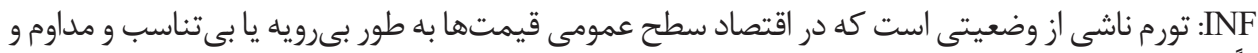

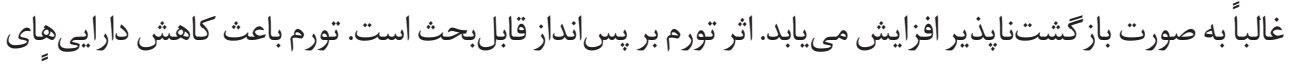

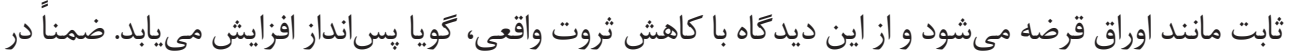

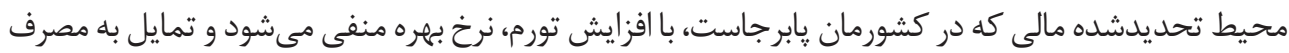

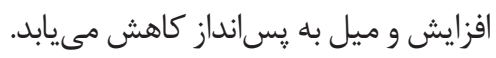

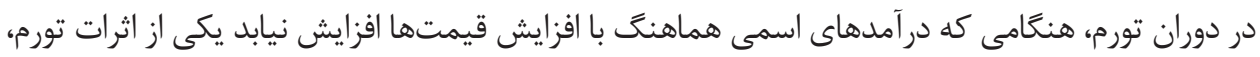

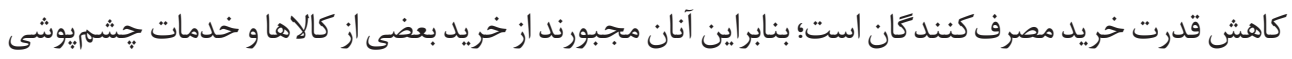

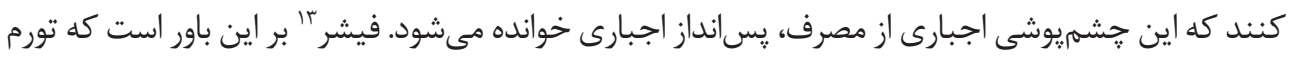

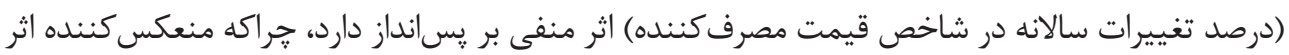

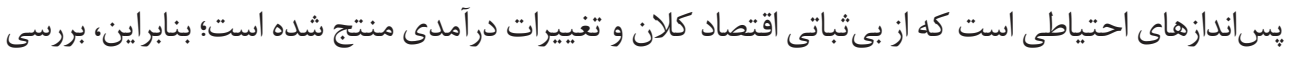
تورم بيشتر موضوعى تجربى است.

\section{r-r-1 - - روش فيلتر هودريك يرسكات}

منطق استفاده از فيلتر هودريك يرسكات آن است كه اين روش ميى تواند به تفكيك يكى شوكى مشاهدهشده

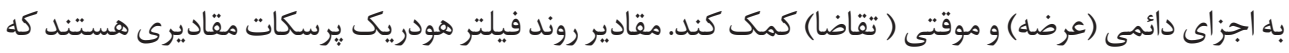
رابطه زير را حداقل كند.

$$
\min \sum_{t=1}^{T}\left(y_{t}-y^{*}\right)^{2}+\lambda \sum_{t=2}^{T-1}\left[\left(y_{t+1}^{*}-y_{t}^{*}\right)-\left(y_{t}^{*}-y_{t-1}^{*}\right)\right]^{2}
$$

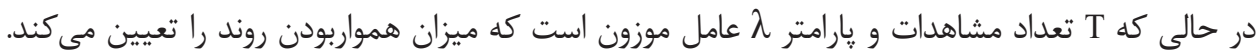

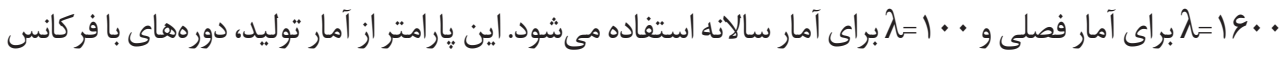

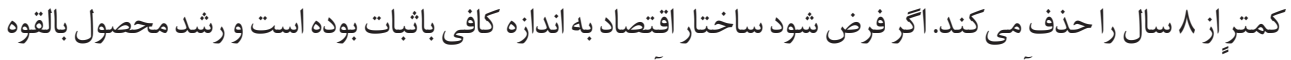

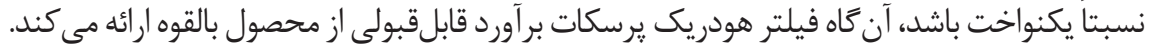

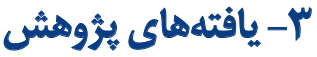

براى تعيين رابطه بين پسانداز و شوكهاى تجارى از رابطه زير كمك گرفته شده است:

$$
P s_{t}=a_{0}+a_{1} \text { Dummy }+a_{2} P s_{t-1}+a_{3} \mathrm{PTOT}_{t}+a_{4} \mathrm{TTOT}_{t}+a_{5} \mathrm{VT}_{t}
$$




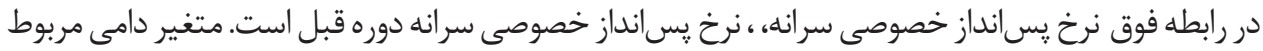

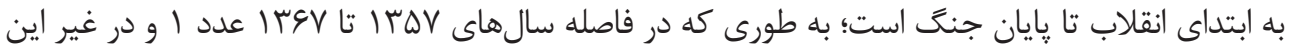

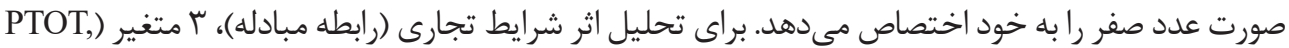
(TTOT, VT

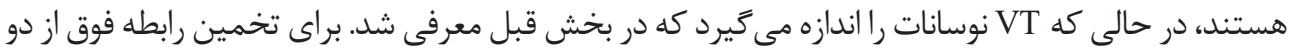
روش حداقل مربعات معمولى و گشتاورهاى تعميميافته استفاده شده است دان.

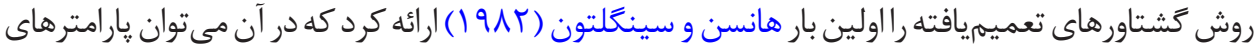

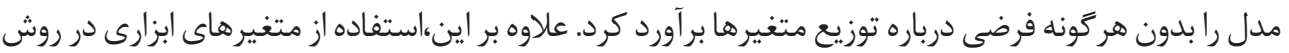

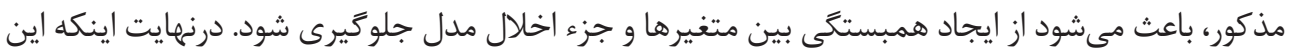

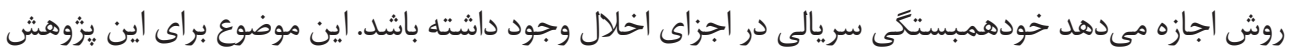

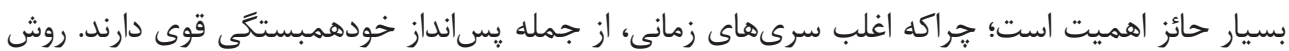

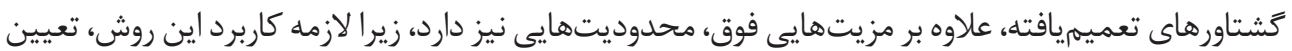

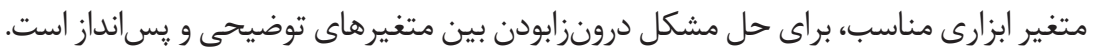

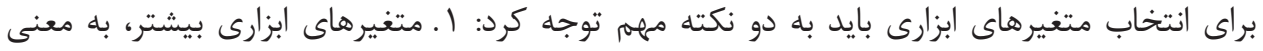

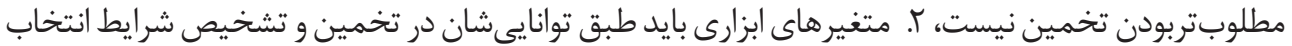

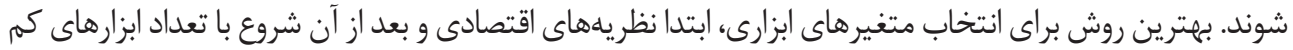

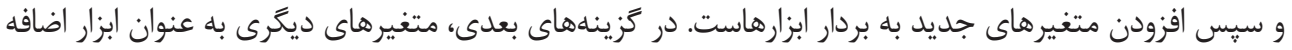

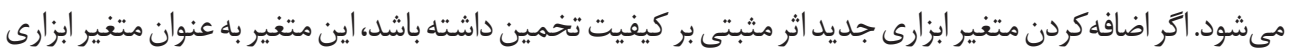

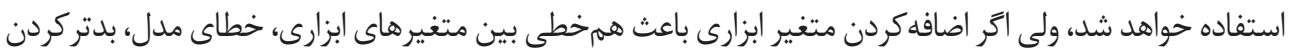

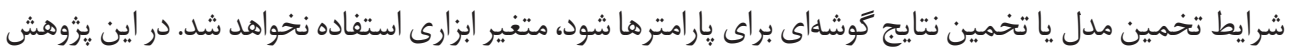

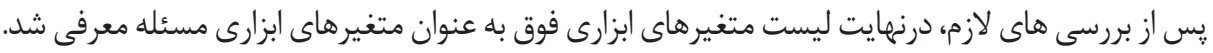

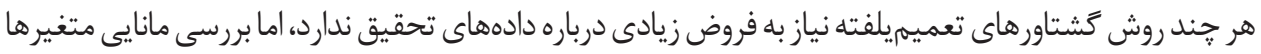

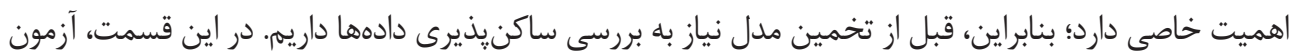

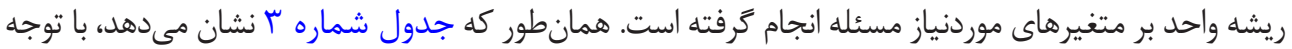

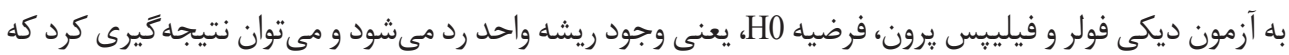

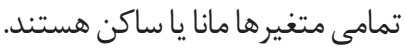

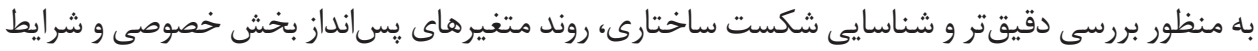

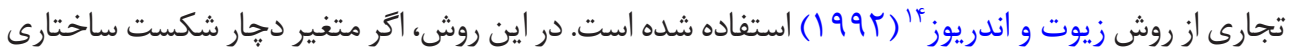

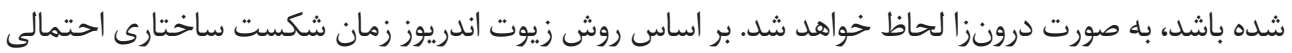


جدول r. بررسى مانايى متغيرهاى مدل

\begin{tabular}{|c|c|c|c|}
\hline آزمون PP & أزمون ADF & وضعيث & ن ام متغير \\
\hline$-\Delta / A \Delta$ & $-\Delta / 9 A$ & با عرض از هبدأ وروند & PS \\
\hline$-9 / \pi \Delta$ & $-1 r / 4 A$ & باعرض از هبدأ و روند & TOTт \\
\hline$-\Delta / \Lambda \Delta$ & $-p / 9$. & باعرض از مبدأ وروند & DEP \\
\hline$-8 / 98$ & $-H / F A$ & باعرض از مبدأ وروند & PTOT \\
\hline$-8 / 19$ & $-V / F)$ & باعرض از مبدا و روند & VTот \\
\hline$-1 \% / \pi 9$ & $-N Q$ & با عرض از مبدأ و روند & RPCY \\
\hline $11 / 9$. & $\Delta / \cdot 9$ & با عرض ازٔ مبدأ و روند & M2GDP \\
\hline - & $-r / q \Delta$ & با عرض ازز مبدأ و روند & INF \\
\hline
\end{tabular}

|ct

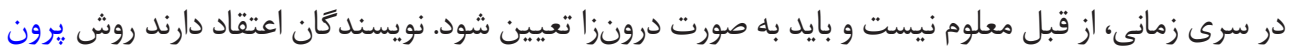

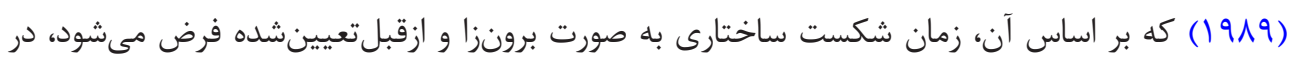

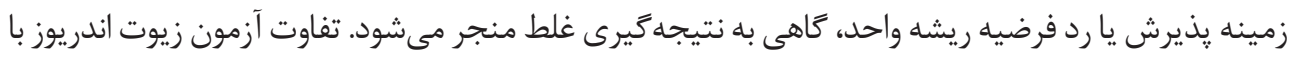

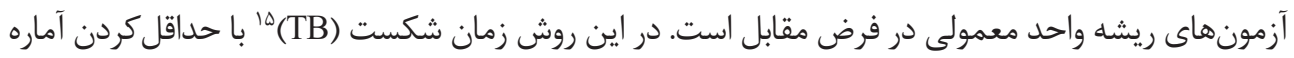

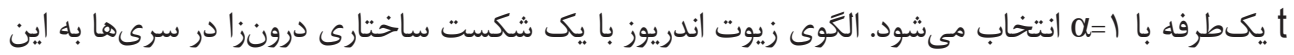
صورت است:

$H_{0}: y_{t}=\mu+y_{t-1}+e_{t}$

H1:

Model $A: y_{t}=\hat{\mu}^{4}+\hat{\theta}^{4} D U_{t}\left(\hat{T}_{b}\right)+\hat{\beta}^{A} t+\hat{\alpha}^{A} y_{k^{\prime}}+\sum_{j=1}^{k} \hat{C}^{A} \Delta y_{t-j}+\hat{e}_{t}$

Model $B: y_{t}=\hat{\mu}^{B}+\hat{\beta}^{B} t+\hat{y}^{B} D T_{t}\left(\hat{T}_{b}\right)+\hat{\alpha}^{B} y_{t-1}+\sum_{j=1}^{k} C^{\bar{B}}{ }_{j} \Delta y_{t-j}+\hat{e}_{t}$

Model $C: y_{t}=\hat{\mu}^{C}+\hat{\theta}^{C} D U_{t}\left(\hat{T}_{C}\right)+\hat{\beta}^{C} t+\hat{y}^{c} D U_{t}\left(\hat{T}_{C}\right) \hat{\alpha}^{C} y_{t-1}+\sum_{j=1}^{k} \hat{C}^{C} \Delta y_{t-j}+\hat{e}_{t}$

همانطور كه روابط مذكور نشان مىدهد، الكوى A تغيير زمانى را در عرض از مبدأ نشان مىدهد و الحَوى

15. Time of Break 


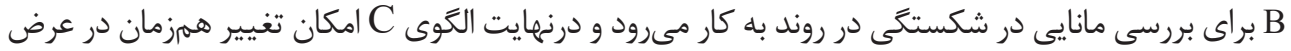

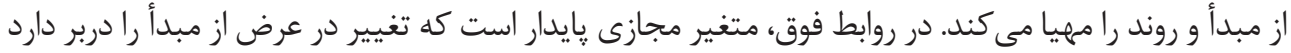

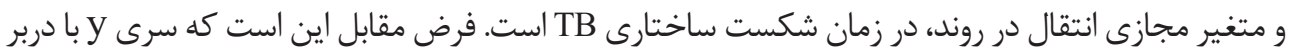

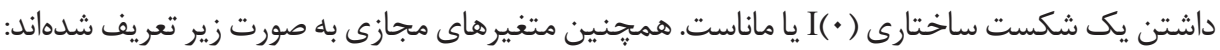

$$
\begin{aligned}
& D T_{t}=\left[\begin{array}{l}
1 \text { if } t>T B \\
0 \text { if } t \leq T B
\end{array}\right. \\
& D T_{\bar{t}}=\left[\begin{array}{c}
t-T B \text { if } t>T B \\
0 \text { if } t \leq T B
\end{array}\right.
\end{aligned}
$$

در اين آزمون اخر آماره م معنادار باشد، فرض صفر رد خواهد شد. همانطور كه اشاره شد در اين آزمون زمان

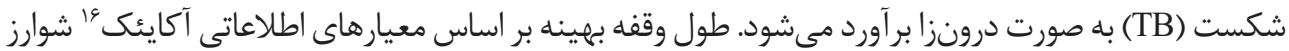

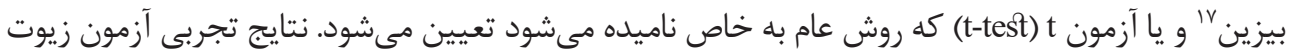

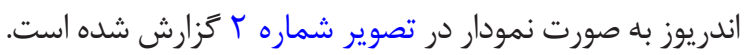

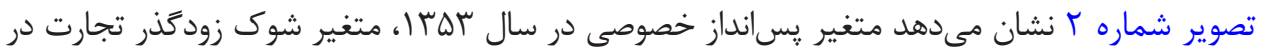

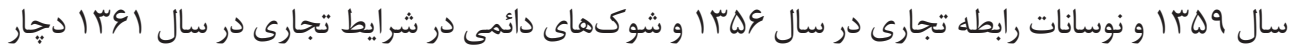

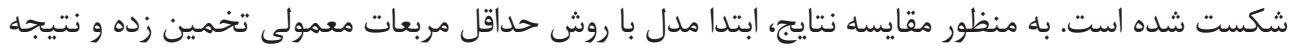

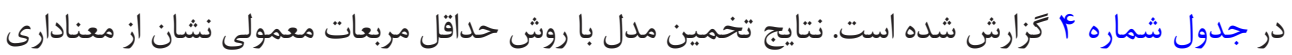

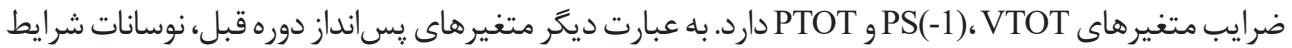

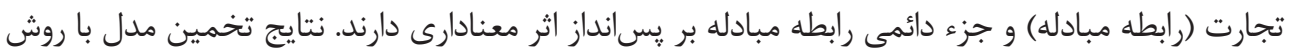

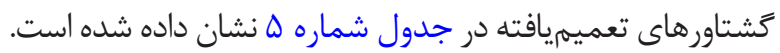

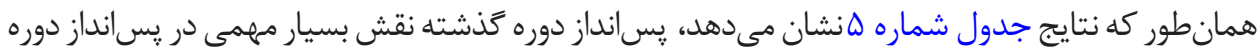

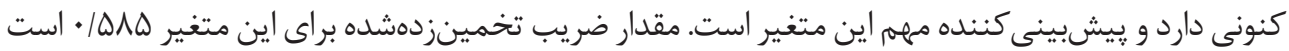

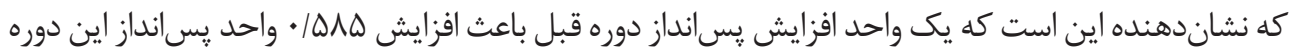

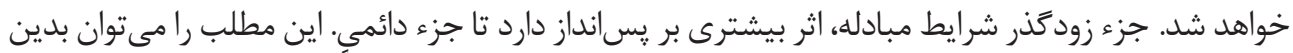

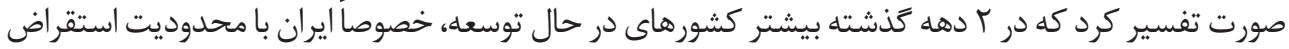

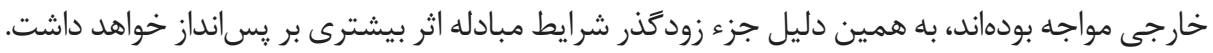

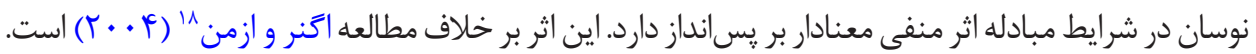




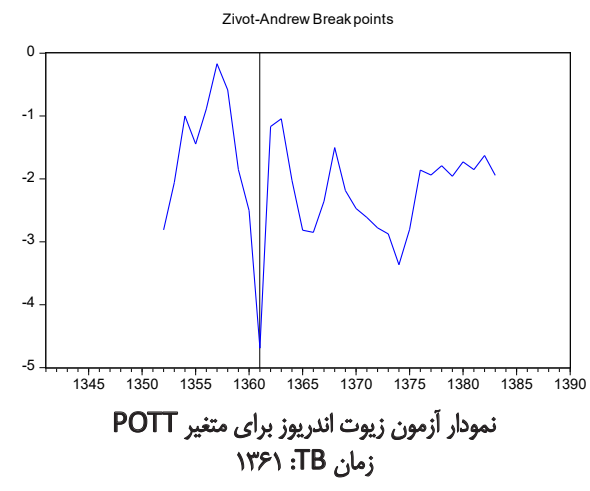

Zivot-Andrew Break points

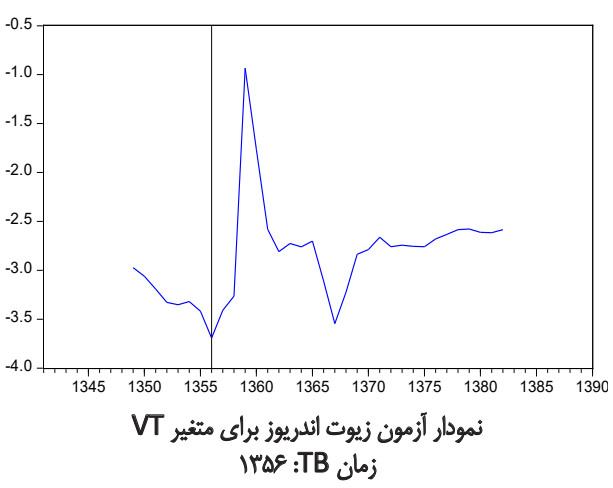

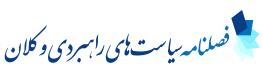
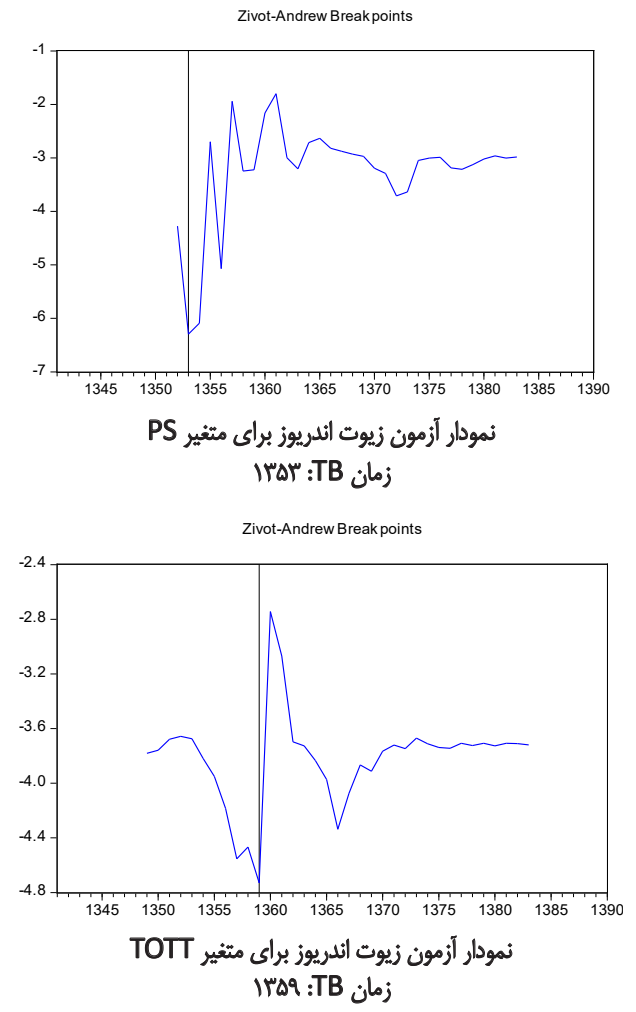

تصوير r. تعيين شكستهاى ساختارى در متغيرهاى اصلى مدل جدول P. نتايج تخمين مدل با روش حداقل مربعات معمولى

\begin{tabular}{|c|c|c|}
\hline 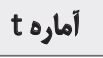 & OLايج تخمين با روش OLS & ضرايب \\
\hline$-1 / 199$ & $-+1 \cdot+\mu^{\mu}$ & C (ضريب ثابت) C \\
\hline P/ATY &. $\mid \Delta E 1$ & PS(-1) \\
\hline.$/ m$ & $.0 . t$ & тотт \\
\hline T/AAS & .1 .11 & РТОТ \\
\hline \multirow[t]{3}{*}{ - Y/ATA } & $-.1 \cdot 1 \mathrm{~V}$ & VTOT \\
\hline & - $/$ A & $\overline{\mathbf{R}}$ \\
\hline & $\mathrm{r} / \cdot 1$ & آماره دوريين واتسون (D.W) \\
\hline
\end{tabular}

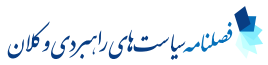

منبع: يافتههاى يُونش 
جدول ه. نتايج تخمين مدل كشتاورهاى تعميهريافته

\begin{tabular}{|c|c|c|c|c|}
\hline اجتمال آماره أزمون لـ & آماره آزمون J J & to أهاره & تثايج تخمين با روش كتشتاورهاى & ضرايب \\
\hline.$/ 290$ & D/Ner & HI/Aه & - IQAS & PS(-1) \\
\hline - & - & $1 . / \Delta r$ & 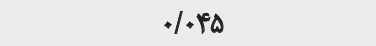 & TOTT \\
\hline - & - & $r \Delta / 1$ & $1 .+9$ & Dummy \\
\hline - & - & $r g / T V$ & $\% 1$ & РТОT \\
\hline - & - & $-M e / a r$ & -1.80 & VTOT \\
\hline
\end{tabular}

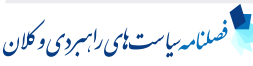

منبع: يافتههاي يُروهش

در جدول شماره ه علاوه بر مقادير عددى برآوردشده براى یارامترها، در دو ستون آخر جدول، مقدار آماره J و

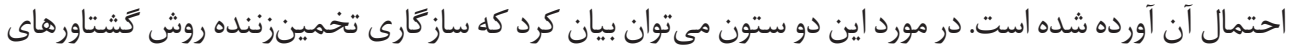

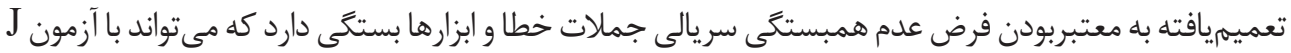

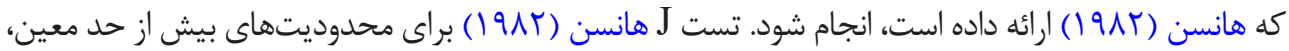

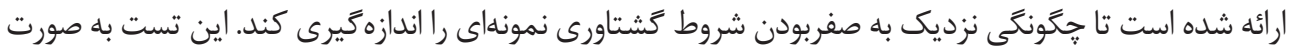
زير قابلبيان است:

$$
n J_{n}\left(\Theta_{G M M}\right) \rightarrow \chi^{2}(r-l)
$$

در رابطه فوق، مقدارى است كه تابع زيان را حداقل مى كند. تحت فرضيه صفر E[h(x,

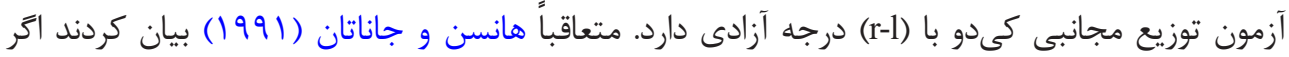

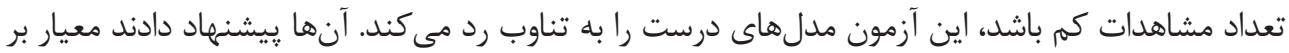

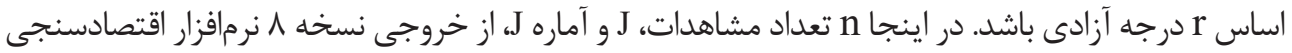

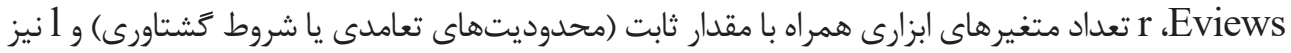

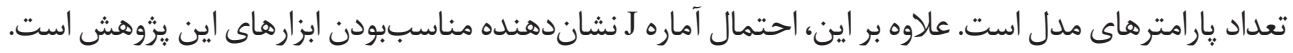

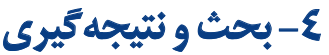

در اين مقاله، به منظور بررسى عوامل اثر گذار بر :سانداز خصوصى سرانه در فاصله سالهاى أبسا تا سوس|

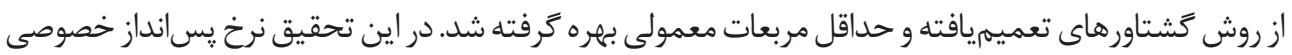

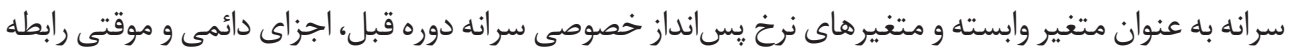
مبادله و نوسانات نسبت صادرات به توليد ناخالص داخلى و متغير دامى (براى دوره شروع انقلاب اسلامى تا پايان 


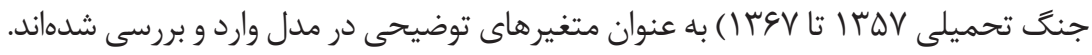
نتايج تخمين مدل با هر دو روش نشان از معنادارى متغيرهاى توضيحى دارد؛ به طورى كه مى توان نتيجه

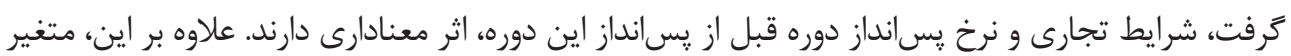

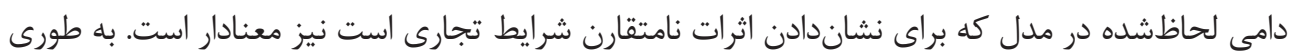

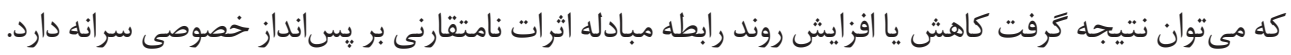

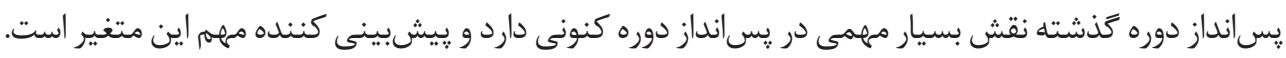
جزء زودكذر شرايط مبادله اثر بيشترى بر يسانداز دارد تا جزء دائمى. اين مطلب را مى توان بدين صورت

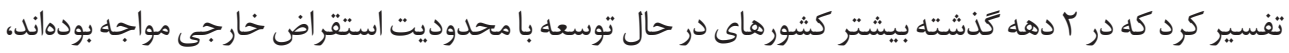

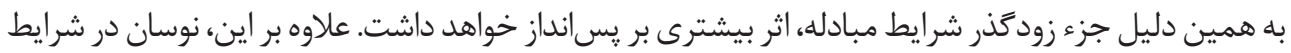
مبادله اثر منفى معنادار بر يسانداز دارد.

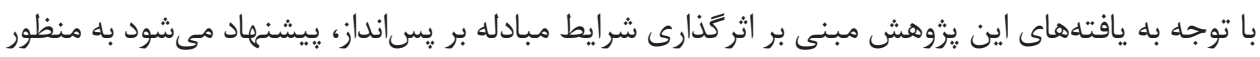

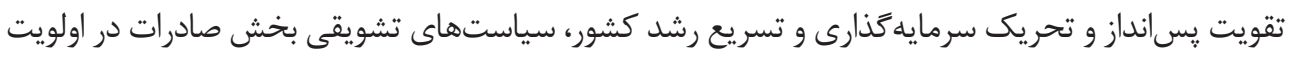

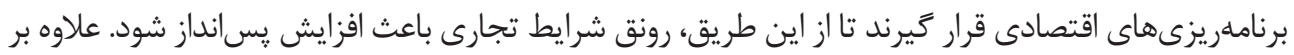

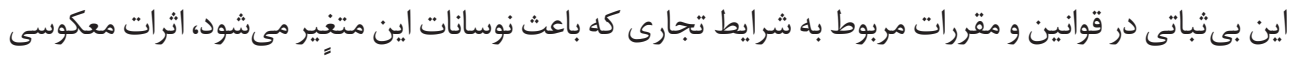

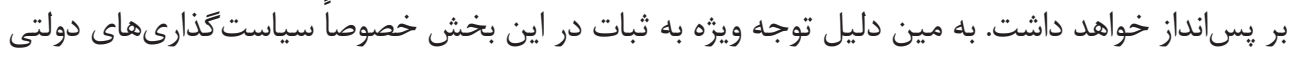
بيش از ييش احساس مىشود.

ماحظات اخلاقى

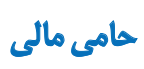

اين مقاله حامى مالى ندارد.

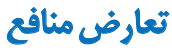

بنا به اظهار نويسندَان، در اين مقاله هيجَّونه تعارض منافعى وجود ندارد. 


\section{References}

Abbasi, A., Mohammadi, T., \& Darvishmanesh, A. (2012). [Investigating the impact of uncertainty of oil revenues on the private sector savings of OPEC member states during 1990-1990 (Persian)]. Financial Economics Journal, 6(19), 59-88.

Abrishami, H., \& Namvar, M. (2004). [The determinants of private savings with emphasis on the performance of financial markets in Iran (Persian)]. Journal of Economic Research, 39(73), 1-35.

Adler, G., \& Magud, M. N. E. (2013). Four decades of terms of trade booms: Saving-investment patterns and a new metric of income windfall. Washington: International Monetary Fund. [DOI:10.5089/9781484356241.001]

Agenor P. R., \& Aizenman, J. (2004). Savings and the terms of trade under borrowing constraints. Journal of International Economics, 63(2004), 321-40. [DOI:10.3386/w7743]

Athukorala, P. C., \& Sen, K. (2004). The determinants of private saving in India. World Development, 32(3), $491-503$. [DOI:10.1016/j.worlddev.2003.07.008]

Bahrami, J., \& Aslani, P. (2005). [Determinants of private sector's saving in Iran (Persian)]. Economic Research, 7(23), 119-45.

Bulir, A., \& Swiston, A. (2006). What explains private draving in Mexico? Washington: International Monetary Fund.

Chowdhury, A. (2015), Terms of trade shocks and private savings in the developing, Countries. Journal of Comparative Economics, 43(4), 1122-34. [DOI:10.1016/j.jce.2015.02.006]

Chowdhury, A. (1993). Does exchange rate volatility depress trade flows? Evidence from error-correction models. The Review of Economics and Statistics, 75(4), 700-6. [DOI: 10.2307/2110025]

Dayal-Gulati, A., \& Thimann, Ch. (2006). Saving in Southeast Asia and Latin America compared: searching for policy lessons. Washington: International Monetary Fund.

Ehsani M. A., \& Khalili Asl, M. (2017). [The effect of income risk on gross domestic saving rate: A case study of Iran (Persian)]. Journal of Economic Policy, 8(16), 1-19.

Hansen, L. P., \& Jagannathan, R. (1991). Restrictions on inter temporal marginal rates of substitution implied by asset returns. Journal of Political Economy, 99, 225-262.

Hansen, L. P., \& Singleton K. J. (1982). Generalized instrumental variables estimation of nonlinear rational expectations models. Econometrica, 50(5), 1269-86. [DOI:10.2307/1911873]

Harberger, A. (1950). Currency depreciation, income and the balance of trade. Journal of Political Economy, 58(1), 47-60. [DOI:10.1086/256897]

Hooshmandi, H. (2009). [A research on factors, affecting national savings in Iran (Persian)]. Quarterly Journal of Economical Modeling, 2(6), 177-204.

Kwack, S. Y., \& Lee, Y. S. (2005). What determines saving rates in Korea? The role of demography. Journal of Asian Economics, 16(5), 861-873. [DOI:10.1016/j.asieco.2005.08.014]

Lahiri, A. K. (1989). Dynamics of Asian savings: The role of growth and age structure. Staff Papers, 36(1), $228-61$.

Laursen, S., \& Metzler, L. A. (1950). Flexible exchange rates and the theory of employment. The Review of Economics and Statistics, 32(4), 281-99. [DOI:10.2307/1925577] 
Loayza, N., Schmidt Hebbel, K., \& Servén, L. (2000). Saving in developing countries: An overview. The World Bank Economic Review, 14(3), 393-414. [PMID]

Mojtahed, A., \& Karami, A. (2003). [Evaluation of variables affecting the national saving behavior in Iran's economy (Persian)]. Iranian Journal of Trade Studies, 27(3), 1-28.

Narayan, P. K., \& Siyabi, S. A. L. (2005). An empirical investigation of the determinants of Oman's national savings. Economics Bulletin, 3(51), 1-7.

Paul, R. J. (2004). A time-series approach to the determination of savings rates. International Economic Journal, 18(2), $147-59$. [DOI:10.1080/1016873042000228303]

Perron, P. (1989). The great crash, the oil price shock and the unit root hypothesis. Econometrica 57(6), 1361-401. [DOI:10.2307/1913712]

Piraee, Kh., \& Keshavarzi M. (2013). [Determinants of private saving in Iran with emphasis on real exchange rate and borrowing constraints (Persian)]. The Macro and Strategic Policies, 1(1), 63-92.

Sobhani, H., \& Barkhordari, M. R. (2011). [Review over effective factors on saving in private sector iran's oil economy (Persian)]. Journal of Economic Research, 46(1), 23-44.

Zivot, E., \& Andrews, D. W. K. (1992). Further evidence on the great crash, the oil-price shock, and the unit-root hypothesis. Journal of Business \& Economic Statistics, 10(3), 251-70. [DOI:10.2307/1391541] 
This Page Intentionally Left Blank 